\title{
On the probabilistic distribution of loads on a marine riser
}

José Manuel Cabrera-Miranda ${ }^{a, b}$ and Jeom Kee Paik ${ }^{a, b, c, *}$

a Department of Naval Architecture and Ocean Engineering, Pusan National University, Busan 46241, Republic of Korea

${ }^{b}$ The Korea Ship and Offshore Research Institute (The Lloyd's Register Foundation Research Centre of Excellence), Pusan National University, Busan 46241, Republic of Korea

${ }^{c}$ Department of Mechanical Engineering, University College London, London WC1E 7JE, UK

* Corresponding Author. Tel.: +82 51510 2429, Cell: +82 103853 8757, Fax: +82 515187687

E-mail addresses: cabrera@pusan.ac.kr (JM Cabrera-Miranda), jeompaik@pusan.ac.kr (JK Paik) 


\section{Abstract}

While in service, marine risers are subjected to various types of loads, such as axial tension and bending moments arising from waves, winds, and currents in association with the motions of the offshore platform. They are also subjected to internal and external pressure loads caused by internal flows and external water pressure. The characteristics of the loads on a marine riser are essentially probabilistic in nature, as they involve several uncertainties associated with random variables. The aim of this study is to quantify the probabilistic distribution of loads on a marine riser to aid determination of the nominal values of design loads. Two methods are investigated. The first is to select a set of credible scenarios in association with site-specific metocean data on an offshore platform, and then perform dynamic riser analysis to describe the probabilistic distribution of the loads. The second is to calculate a metamodel to predict the loads as a function of multiple input variables, a method that can also characterize the probabilistic load distribution by running a Monte Carlo simulation. Both approaches are compared via a numerical example of a marine drilling riser in ultra-deep water; the results show that metamodel-based method is the most appropriate to describe neatly the loads at low probability of exceedance. The characteristics of the loads on a marine riser are observed to be highly random and significantly affected by environmental and functional conditions. Hence, the design loads must be determined by considering the marginal probabilistic density function of all such parameters.

Keywords: Offshore structure, Marine drilling riser, Site-specific metocean data, Probabilistic load distribution.

\section{Introduction}

Risers constitute key equipment in offshore drilling and production facilities. While in service, they are subjected to axial tension and bending moments arising from waves, winds, and currents in association with the motions of the offshore platform, as shown in Fig. 1. They are also subjected to internal and external pressure loads caused by internal flows and external water pressure. 

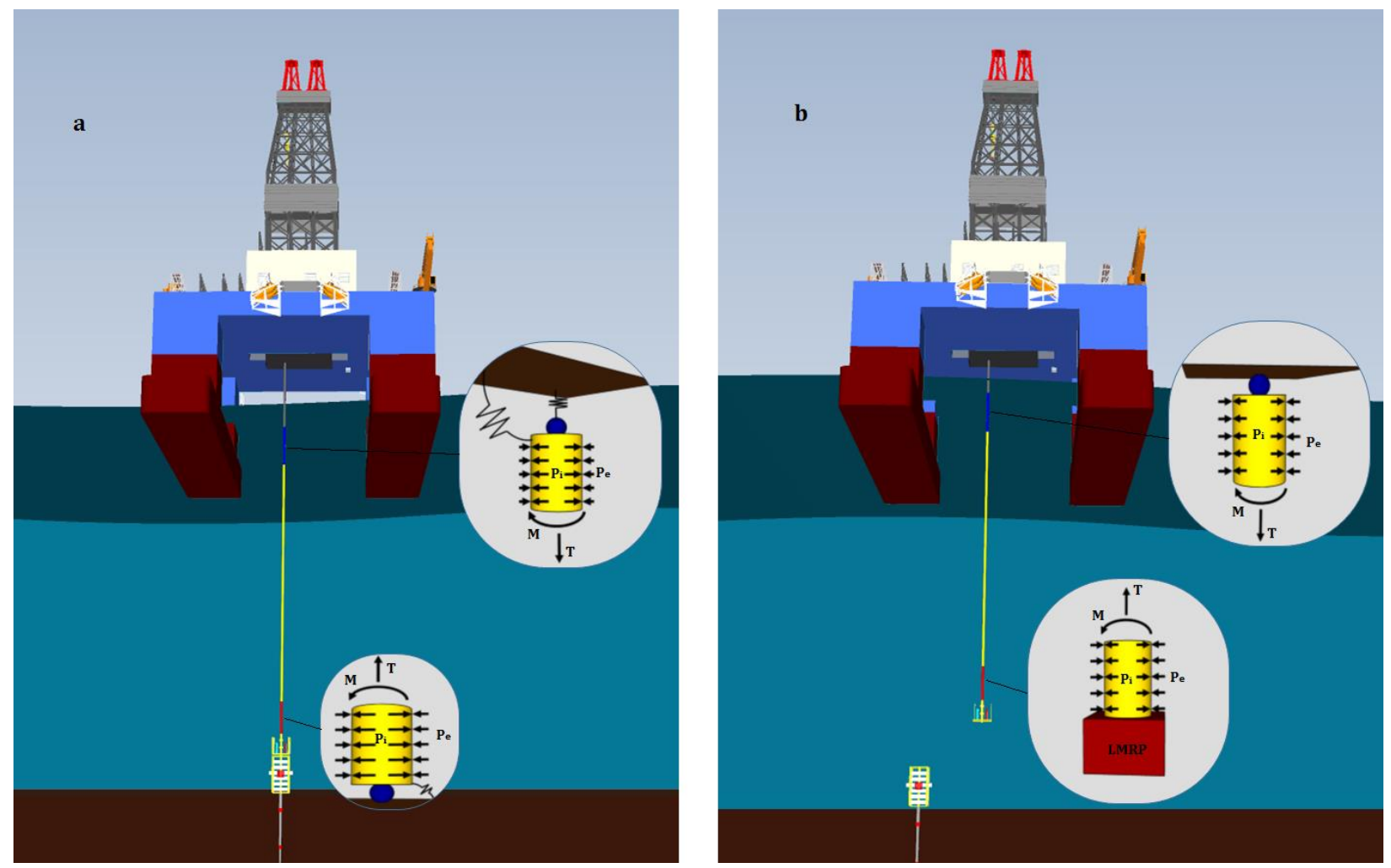

Fig. 1. Typical marine drilling riser operated from a semi-submersible drilling vessel in (a) connected and (b) disconnected mode.

A number of useful studies are reported in the literature. Y. Wang et al. (2015a, 2014a, 2014b) studied the mechanics of marine drilling risers during installation. Mao et al., $(2016,2015)$ studied the mechanics of marine drilling risers in site and Vortex Induced Vibrations (VIV) as well. Tensioner systems that are relevant for the dynamics of top-tensioned risers have been studied by Guimarães Pestana et al. (2016) and Lee et al. (2015). Wei et al. (2012) employed the experimental method to analyze the hydrodynamic performance of a floating drilling production storage and offloading unit connected to a riser. Connaire et al. (2015) develop a method to predict riser response with coupled axial, bending and torque deformations. Dong et al. (2013) derived the equations that describe the connection of a flexible riser to a floating production system. J. Wang et al. (2015a, 2015b, 2014) studied the quasi-static response of steel lazy-wave risers. Li and Low (2014) studied low-frequency fatigue of steel catenary risers. Dynamics of the sagbend region of steel catenary risers has been addressed by Katifeoglou and Chatjigeorgiou (2015, 
2012). Bai et al. (2014) analyzed the response of drill pipe during subsea manifold installation. Guo et al. (2014) and Ye et al. $(2014,2013)$ have also studied the installation of risers. Riser accidental loads have been investigated by Liu et al. (2013) for grounding and by Chen et al. (2016, 2014) for coiled-tubing loads. Bai et al. (2015), Baker and Liddle (2015), Clarke et al. (2011) and Costache et al. (2016) have studied the use of flexible pipe on risers. Y. Chen et al. (2015), Pham et al. (2016), Sun et al. (2014) and Zhang et al. (2015) studied the use of composite materials for the fabrication of risers. Special attention has been paid to VIV; W. Chen et al. $(2015,2014)$ studied coupled floater motions and VIV; Gu et al. (2013b) and Josefsson and Dalton (2010) focused on the development of analytical models to assess VIV; Ma and Spencer (2014), Wang and Xiao (2016), Xu and Cater (2016) employed numerical methods; Gu et al. (2013a) employed towing tank experiments; Gao et al. (2016) and Park et al. (2015) studied the use of helical strakes to suppress VIV, whilst Dai et al. (2015) opted for the use of time-delay feedback controller. Riser parametric excitation has received plenty of attention; Kuiper et al. (2008) and Y. Wang et al. (2015b) studied single frequency parametric excitation, and Yang et al. $(2016,2013)$ and Yang and Xiao (2014) studied multi-frequency parametric excitation.

Furthermore, scholars have dealt with long-term distribution of loads. Farnes and Moan (1993) employed a metamodel-based approach to investigate long-term flexible riser response. Gao and Low (2016) and Shi et al. (2014) have proposed methods for long-term riser fatigue analysis. Li and Low (2012) studied fatigue on steel catenary risers and (Nazir et al., 2008) did so for top-tensioned risers. Mousavi et al. (2016) proposed a simplified method for reliability analysis of steel catenary risers. Low and Srinil (2016) investigated the riser reliability associated to VIV. Xiao and Yang (2014) employed a reliability analysis to study the parametric instability of top-tensioned risers.

In extreme conditions, risers can fail to sustain the loads exerted on them, with catastrophic consequences. Determining the adequate values of design loads is therefore of paramount importance. Also, in today's industry practice, reliability analyses are required to evaluate the integrity and system performance of risers in association with the uncertainties inherent in random design variables. In this regard, the quantification of loads in a probabilistic manner is essential. 
In this paper, we introduce two methodologies for determining the probabilistic distribution of loads on marine risers. We estimate the probability of the exceedance curves for effective tension, bending moments, and internal overpressure. These loads must account for the uncertainties of site-specific metocean and functional variables, and they must also be compatible with current design and operating practices. First, we propose a dynamic analysis-based method in which the load distribution is estimated from the selection of a relatively few scenarios; we take as reference a previous paper in which loads were estimated for other marine structures (Paik et al., 2015). In order to improve the upper tail of the distribution, we use a second approach so called metamodel-based method that has already been applied to investigate loads on risers (Farnes and Moan, 1993; Yang and Zheng, 2011). The novel aspect of this study is that we account for the load reduction during riser disconnection mode in non-permanent systems. Moreover, load probabilistic distribution of marine drilling risers has not been discussed in the literature.

The remainder of this paper is organized as follows. In Section 2, we propose the two methods for determining the probabilistic distribution of riser loads. In Section 3, we solve an applied example of a riser that operates in a harsh, ultra-deep water environment. In Section 4, we compare the results of the two methods, and explore the role of the most influential input parameter. Finally, in Section 5 we offer concluding remarks on the proposed methods.

\section{Methods of quantifying the probabilistic distribution of loads on a marine riser}

Two methods of quantifying the probabilistic distribution of loads on a marine riser are considered here. The first is based on dynamic analysis of select riser scenarios, and the second is based on metamodels.

\subsection{Dynamic analysis-based method}

The first and simplest approach is a dynamic analysis method that consists of selecting a sufficient number of credible scenarios to account for a random environment and then performing time-domain dynamic analyses. This method is inspired by the ideas proposed by Paik et al. (2015), who used similar 
methodology to investigate sloshing loads on liquefied natural gas floating production, storage, and offloading units (LNG FPSOs). The method's procedure is described in Fig. 2, delimited by the dotted line.

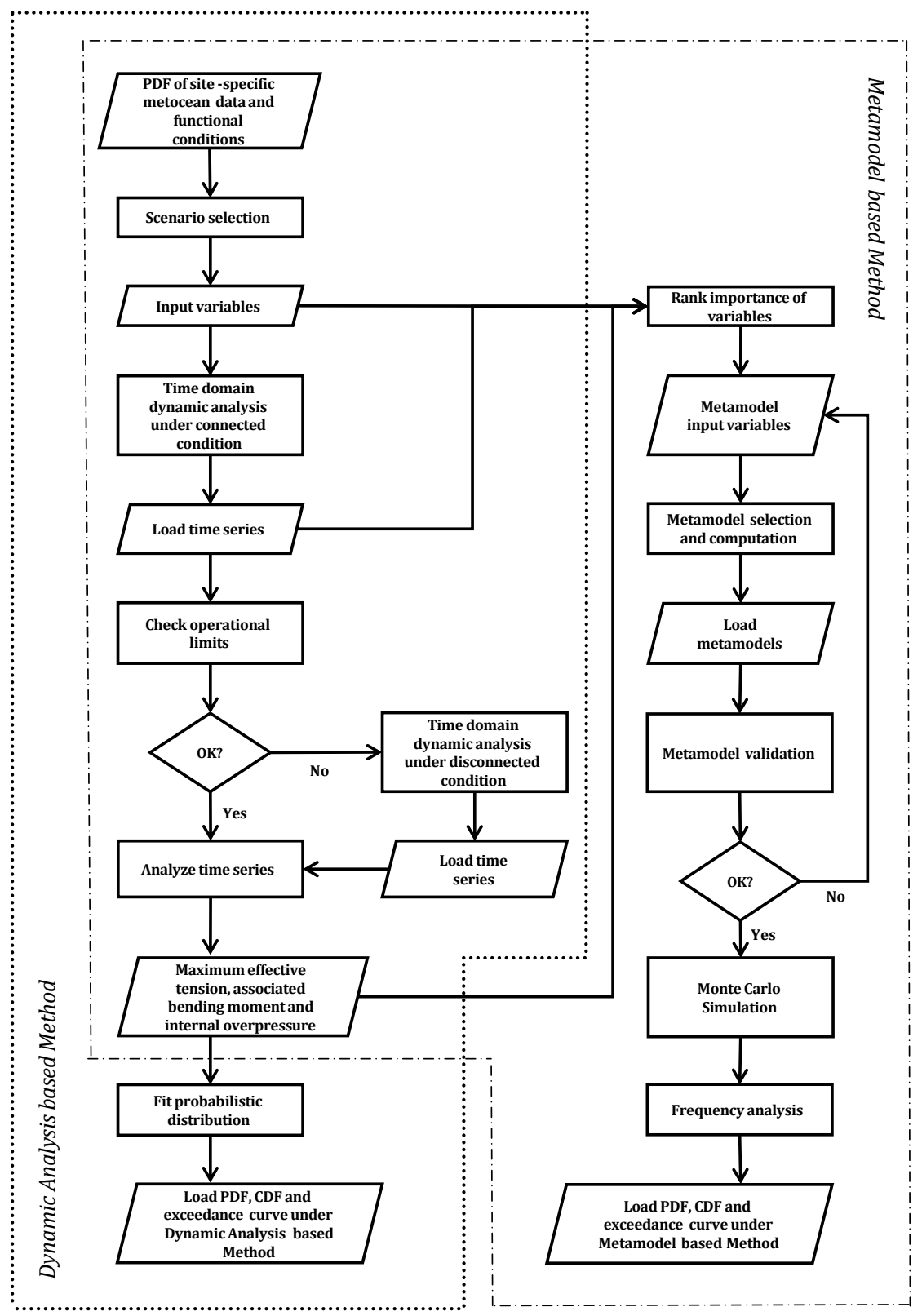

Fig. 2. Procedures for determining the probabilistic distribution of loads on a marine riser.

\subsubsection{Selection of scenarios}

Given that it is not feasible to perform an infinite number of dynamic analyses, we select credible scenarios that characterize the probabilistic distribution of the input variables and the riser response. We 
choose the site-specific metocean conditions that determine such dynamic riser responses as the significant wave height, wave mean zero crossing period, wind speed, and current speed and the direction of each of these environmental forces. Moreover, the riser motions can be influenced to a large degree by the functional conditions. Therefore, we account for the uncertainties in riser top-tension, which strongly influence system stiffness; internal fluid density, which can modify the mass of the structure; and the stiffness of the dynamic positioning (DP) system, which plays as essential role in the floater's horizontal offset around its main position. All input parameters are described by their marginal probability density function (PDF).

We adopt Latin hypercube sampling (LHS) to select a representative number of scenarios. LHS is a popular sampling method in the design of computer experiments, and it has been successfully employed to generate risk assessment scenarios for offshore facilities (Paik et al., 2011; Seo et al., 2013). An indepth discussion of LHS can be found in Fang et al. (2006), and Shields and Zhang (2016).

\subsubsection{Time-domain analysis in connected mode}

Time-domain dynamic riser analysis is performed for each scenario using ANSYS Aqwa to obtain time series of the motions and loads. At the first stage, the hydrodynamic properties of a floating offshore platform are calculated by means of a 3-dimensional panel method based on potential theory in frequency domain. Next a time-domain simulation of 3 hours' physical time is executed in the riser connected mode, as illustrated in Fig. 1(a). Such a structure is subjected to irregular waves defined by a Pierson-Moskowitz spectrum, constant wind speed, linearly sheared current, and random floater motions. The direct hydrodynamic forces acting on the riser comprise Morison inertia forces from waves and Morison drag forces from waves and the current.

For drilling risers, the connected mode allows communication between the wellhead and the offshore platform during drilling operations. Furthermore, drilling mud is circulated through the riser to the well to achieve bottom hole stability by counteracting the formation pressure. For production risers, hydrocarbons or water are the fluids conveyed, and therefore the degree of external pressure is normally higher than that of internal pressure. 


\subsubsection{Time-domain analysis in disconnected mode}

We then identify scenarios in which a permanent riser has to operate in disconnected mode. We compare the connected analysis results for a drilling riser against the API RP 16Q (American Petroleum Institute, 1993) design and operating guidelines (method B). A drilling riser would not be able to operate in scenarios that do not fulfill the stated criteria, and we therefore need to update their dynamic analysis in disconnected mode. This new condition significantly reduces the loads on the marine riser because its slender structure is no longer subjected to constraint at the bottom end, and flooding of the main conductor makes the internal pressure match the external pressure. A riser in disconnected mode is illustrated in Fig. 1(b).

When an offshore platform is about to face a severe storm, planned riser disconnection procedures are implemented. When a severe storm hits inadvertently, however, emergency disconnection takes place if the vessel offset becomes excessive. In this situation, the blowout preventer secures the well, and the riser is quickly disconnected from the preventer. The drilling mud is then released into the ocean, which has negative consequences for the environment, but protects the facility from more dangerous circumstances.

Some production risers are also designed to be disconnectable to reduce potential loads. For risers of a permanent character, this step should be omitted.

\subsubsection{Best-fit probabilistic distribution}

We have now obtained time series of loads in the connected and disconnected mode. The next step is to extract the maximum values of the effective tension, associated bending moment, and static internal overpressure for each scenario. Drilling risers are classified as top-tensioned risers, which means that tension is more relevant than bending. For compliant risers, we can choose the maximum bending moment with associated effective tension, depending on which load dominates the riser response. With regard to pressure, the conveyed drilling mud has a higher density than seawater, and there is therefore net internal overpressure, defined as the difference between the internal and external pressure. Here, we 
neglect the dynamic component that stems from irregular waves. However, external overpressure may be of greater importance for production risers.

Finally, we are able to obtain the best-fit probabilistic distribution for each of the loads by combining a goodness-of-fit test with the Kolmogorov-Smirnov test. The candidate distributions comprise exponential, gamma, lognormal, normal, Weibull, and 3-parameter Weibull distributions. Further details of the statistical analysis can be found in Paik et al. (2004).

\subsection{Metamodel-based method}

The metamodel-based method is essentially devised with the purpose of validating the dynamic analysis-based method. Hence, rather than selecting a few credible scenarios, we perform Monte Carlo simulation (MCS) to sample a large number of input random variables for a metamodel that describes the load. This method relies on the dynamic analysis-based method because it requires the LHS factors and responses that determine the metamodel. The procedure for applying this approach is summarized in Fig. 2 delimited by the dash-dotted line.

\subsubsection{Ranking importance of variables}

We make use of scatter plots and interaction effect plots of the input variables versus load to assess which parameters should be included and which can be neglected in the metamodel. More sophisticated ranking procedures are explained in Fang et al. (2006).

\subsubsection{Metamodel selection and computation}

Let us consider input variables $\mathbf{x}=\left[x_{1}, x_{2}, \ldots, x_{s}\right]$ and load response $y$. There must be a function $y=f(x)$ that, in practice, is difficult or impossible to derive. However, we can use a metamodel that is an approximate function $\hat{y}=g(\mathbf{x})$ to describe $y$ in the domain of interest. To construct a metamodel, we first need to apply a sampling technique to the scenarios, obtain the desired responses through time-domain dynamic riser analysis, and obtain the maximum or associated load. Then, the selected scenarios provide the metamodel with the necessary information to predict the loads at unknown points. 
There are various types of metamodels, including Kriging models, polynomial regression models, local polynomial regression, multivariate spline and wavelets, Bayesian methods, and neural networks (Fang et al., 2006). Yang and Zheng (2011) concluded that the Kriging metamodel is more accurate than the polynomial for nonlinear riser stress-related problems. Accordingly, we use the Kriging metamodel computed by means of the ooDACE Matlab toolbox (Ulaganathan et al., 2015).

\subsubsection{Monte Carlo simulation of loads}

We perform MCS to sample the random input variables of the load metamodel. Then, frequency analysis of the results allows us to readily obtain the PDF and probability of exceedance curve of any load, with accuracy that improves with the number of simulations.

\section{Numerical example}

In this section, we propose an applied example to illustrate the application of the two methods discussed above.

3.1 Riser and semi-submersible drilling vessel characteristics

We investigate the loads on a marine drilling riser system that is operated from a semi-submersible drilling vessel in a harsh environment and water of $3000 \mathrm{~m}$ in depth, as sketched in Fig. 1. In such conditions, the design is driven by the bursting failure mode because of the large drilling fluid column. A riser made of X-80-grade steel with a 21 -inch main conductor outer diameter is considered, with the properties extracted from Permana (2012), as listed in Table 1. The marine riser hangs from a semisubmersible drilling vessel that possesses the typical dimensions of an ultra-deep water drilling rig, as indicated in Table 2 and illustrated in Fig. 1. 
Table 1. Main properties of 21-inch X-80-grade steel riser joints

\begin{tabular}{|c|c|c|c|c|c|c|c|}
\hline Riser type & $\begin{array}{l}\text { Number } \\
\text { of joints }\end{array}$ & $\begin{array}{l}\text { Water } \\
\text { depth }(\mathrm{m})\end{array}$ & $\begin{array}{l}\text { Main conductor } \\
\text { outer diameter } \\
\text { (m) }\end{array}$ & $\begin{array}{l}\text { Main conductor } \\
\text { inner diameter } \\
(\mathrm{m})\end{array}$ & $\begin{array}{l}\text { Dry } \\
\text { weight } \\
\text { (t) }\end{array}$ & $\begin{array}{l}\text { Buoyancy } \\
\text { outer diameter } \\
\text { (m) }\end{array}$ & $\begin{array}{l}\text { Buoyancy } \\
\text { material density } \\
\left(\mathrm{kg} / \mathrm{m}^{3}\right)\end{array}$ \\
\hline $\begin{array}{l}75 \mathrm{ft} \text {. bare } \\
(22.86 \mathrm{~m})\end{array}$ & 2 & $7.7-53.42$ & 0.5334 & 0.0222 & 12.93 & 1.4224 & - \\
\hline $\begin{array}{l}75 \mathrm{ft} .+ \\
\text { buoyancy } \\
\text { rating } 609 \mathrm{~m}\end{array}$ & 23 & $\begin{array}{l}53.42- \\
579.2\end{array}$ & 0.5334 & 0.0222 & 23.95 & 1.4224 & 353 \\
\hline $\begin{array}{l}75 \mathrm{ft} .+ \\
\text { buoyancy } \\
\text { rating } 1219 \mathrm{~m}\end{array}$ & 27 & $\begin{array}{l}579.2- \\
1196.42\end{array}$ & 0.5334 & 0.0222 & 24.95 & 1.4224 & 385 \\
\hline $\begin{array}{l}75 \mathrm{ft} \text { + } \\
\text { buoyancy } \\
\text { rating } 1829 \mathrm{~m}\end{array}$ & 27 & $\begin{array}{l}1196.42- \\
1813.64\end{array}$ & 0.5334 & 0.0222 & 26.45 & 1.4224 & 433 \\
\hline $\begin{array}{l}75 \mathrm{ft} .+ \\
\text { buoyancy } \\
\text { rating } 2438 \mathrm{~m}\end{array}$ & 27 & $\begin{array}{l}1813.64- \\
2460.86\end{array}$ & 0.5334 & 0.0222 & 28.21 & 1.4224 & 489 \\
\hline $\begin{array}{l}75 \mathrm{ft} .+ \\
\text { buoyancy } \\
\text { rating } 3048 \mathrm{~m}\end{array}$ & 23 & $\begin{array}{l}2460.86- \\
2956.64\end{array}$ & 0.5334 & 0.0222 & 29.44 & 1.4224 & 529 \\
\hline $75 \mathrm{ft}$. bare & 1 & $\begin{array}{l}2956.64- \\
2979.5\end{array}$ & 0.5334 & 0.0222 & 12.93 & 1.4224 & - \\
\hline
\end{tabular}

Table 2. Main particulars of hypothetical semi-submersible drilling vessel

\begin{tabular}{ll}
\hline Particular & Dimension \\
\hline Length of pontoons & $115 \mathrm{~m}$ \\
Width of pontoons & $18 \mathrm{~m}$ \\
Height of pontoons & $10 \mathrm{~m}$ \\
Length of columns & $17 \mathrm{~m}$ \\
Width of columns & $18 \mathrm{~m}$ \\
Height of columns & $22.5 \mathrm{~m}$ \\
Deck length & $78.5 \mathrm{~m}$ \\
Deck width & $78 \mathrm{~m}$ \\
Deck height & $7 \mathrm{~m}$ \\
Draft (operational) & $20.5 \mathrm{~m}$ \\
\hline
\end{tabular}

\subsection{Application of dynamic analysis-based method}

We explore the influence of the 11 random variables as listed in Table 3 . The uncertainty in sitespecific metocean data is accounted for by variables $X_{1}, \ldots, X_{8}$, which describe the waves, wind, and current in North Atlantic conditions for worldwide operation. The directional spreading of the sea is approximated by introducing a directional function (Det Norske Veritas, 2010). One of the advantages of using sampling techniques is the methodological selection of environmental force directions. 
It is assumed that the PDFs of the functional conditions are uniformly distributed. The lower and upper limits of internal fluid density $X_{9}$ are taken from the typical mud characteristics in the drilling data handbook (Institut Français du Pétrole, 1999), and the stiffness $X_{11}$ in the surge and sway of the DP system is selected to achieve natural periods that range between $100 \mathrm{~s}$ and $200 \mathrm{~s}$, which are typical values for this type of station-keeping system (Faltinsen, 1990). Variable $X_{10}$ is a factor that multiplies the minimum top-tension and must be larger than 1. After running LHS, we perform time-domain dynamic riser analysis for each scenario. An example of the time series of loads is given in Fig. 3.

Table 3. Probabilistic distribution of input parameters

\begin{tabular}{clll}
\hline Variable & Description & Unit & Distribution \\
\hline$X_{1}$ & Significant wave height & $\mathrm{m}$ & 3-parameter Weibull $(\alpha=3.041, \beta=1.484, \gamma=0.661)$ \\
$X_{2}$ & $\begin{array}{l}\text { Peak period or zero mean crossing } \\
\text { period }\end{array}$ & $\mathrm{s}$ & Log-normal distribution $(\mu=2.1647, \sigma=0.1854)$ \\
& $\begin{array}{l}\text { Wave direction angle with respect } \\
X_{3}\end{array}$ & $\mathrm{rad}$ & DNV directional function $(s=5)$ \\
& $\begin{array}{l}\text { to peak direction } \\
X_{4}\end{array}$ Wind speed & $\mathrm{m} / \mathrm{s}$ & 2-parameter Weibull $(\alpha=9.7344, \beta=2.1393)$ \\
$X_{5}$ & Wind direction & $\mathrm{rad}$ & DNV directional function $(\mathrm{s}=5)$ \\
$X_{6}$ & Current speed at surface & $\mathrm{m} / \mathrm{s}$ & Log-normal distribution $(\mu=-0.808, \sigma=0.2379)$ \\
$X_{7}$ & Current speed at bottom & $\mathrm{m} / \mathrm{s}$ & Log-normal distribution $(\mu=-1.329, \sigma=0.2864)$ \\
$X_{8}$ & Current direction & $\mathrm{rad}$ & DNV directional function $(s=5)$ \\
$X_{9}$ & Internal fluid density & $\mathrm{Kg} / \mathrm{m}^{3}$ & Uniform $(1025,2037)$ \\
$X_{10}$ & Minimum tension factor & - & Uniform $(1,1.5)$ \\
$X_{11}$ & DP stiffness in surge and sway & $\mathrm{N} / \mathrm{m}$ & Uniform $\left(9.3 \times 10^{4}, 5.6 \times 10^{5}\right)$ \\
\hline
\end{tabular}

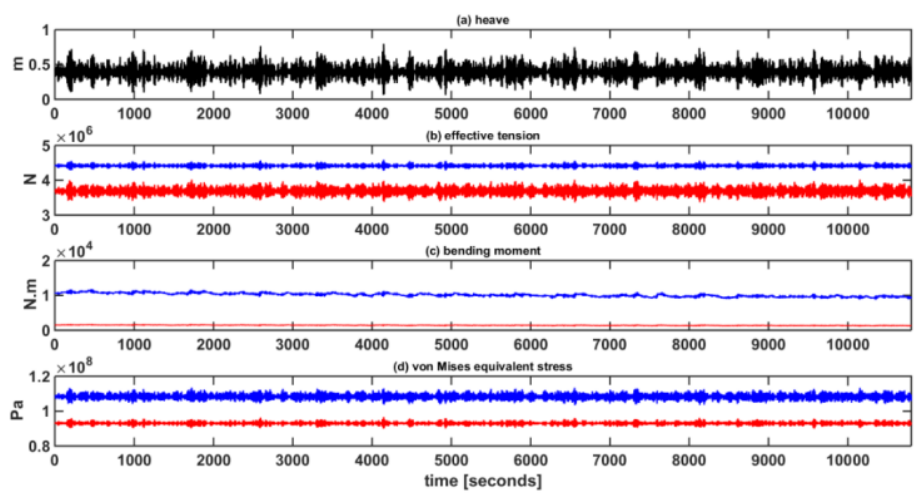

Fig. 3. Responses of semi-submersible drilling vessel (black), riser top joint (blue), and riser bottom joint (red) for scenario 50: (a) heave, (b) effective tension, (c) bending moment, and (d) von Mises equivalent stress. 
We next consider the riser stress and flex joint angles. In Fig. 4, we compare them against the operating limits. As we find that the riser would not be able to fulfill its mission in six of the scenarios, the dynamic analysis is repeated for those ones in disconnection mode. From the corrected time series of the 50 scenarios, we obtain the loads at the top riser joint, where the effective tension is greatest, and at the bottom riser joint, where the internal overpressure can lead to riser failure through bursting.
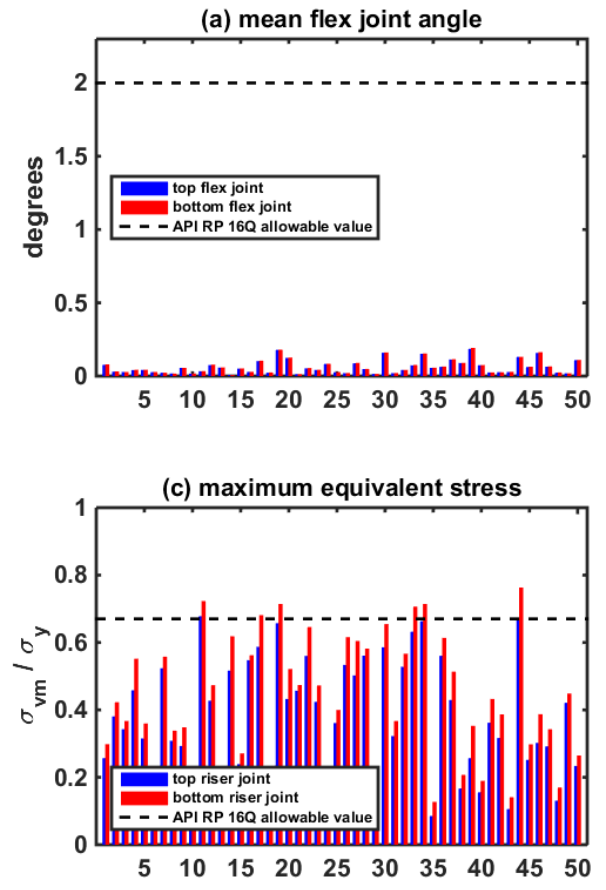

(b) maximum flex joint angle

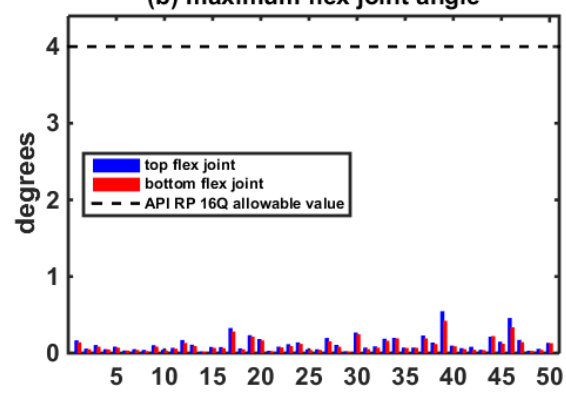

(d) significant dynamic

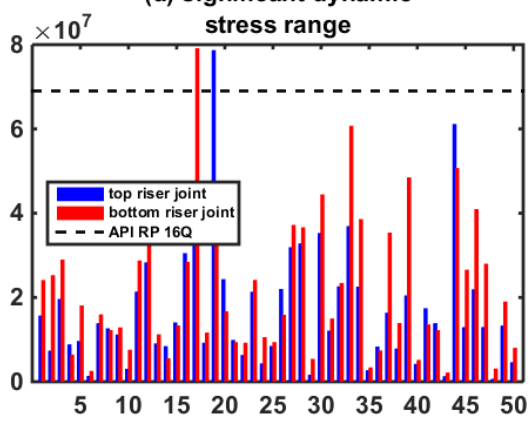

Fig. 4. Check of the limit operating conditions for the 50 scenarios as per API RP $16 Q$.

Hereinafter, we distinguish random riser loads with the following nomenclature: $Y_{1}$ for the effective tension at the top riser joint, $Y_{2}$ for the effective tension at the bottom riser joint, $Y_{3}$ for the bending moment at the top riser joint, $Y_{4}$ for the bending moment at the bottom riser joint, $Y_{5}$ for the internal overpressure at the top riser joint, and $Y_{6}$ for the internal overpressure at the bottom riser joint. The 50 selected scenarios and effective tension loads are summarized in Fig. 5(a). This graph presents rich information on the input 
parameters and responses involved. The elements on the diagonal show the histogram for each variable. For example, the first element in the figure shows the histogram for variable $x_{1}$, which is plotted in more detail in Fig. 5(b).

Elements outside the diagonal in Fig 5(a) present scatter plots that reveal the interaction between a variable in one row and that in a particular column. Particular attention should be paid to the last two rows and last two columns, which display the relation between discrete input parameters $x_{1}, \ldots, x_{11}$ and discrete loads $y_{1}$ and $y_{2}$. For instance, we can observe a positive correlation between variables $x_{9}$ and $y_{1}$, whereas there is a low degree of correlation between variables $x_{5}$ and $y_{2}$ because the data points are dispersed. Fig 5(c) presents an example of load $y_{1}$ as a function of input parameter $x_{1}$, which corresponds to element $(12,1)$ in Fig. 5(a). 
(a)

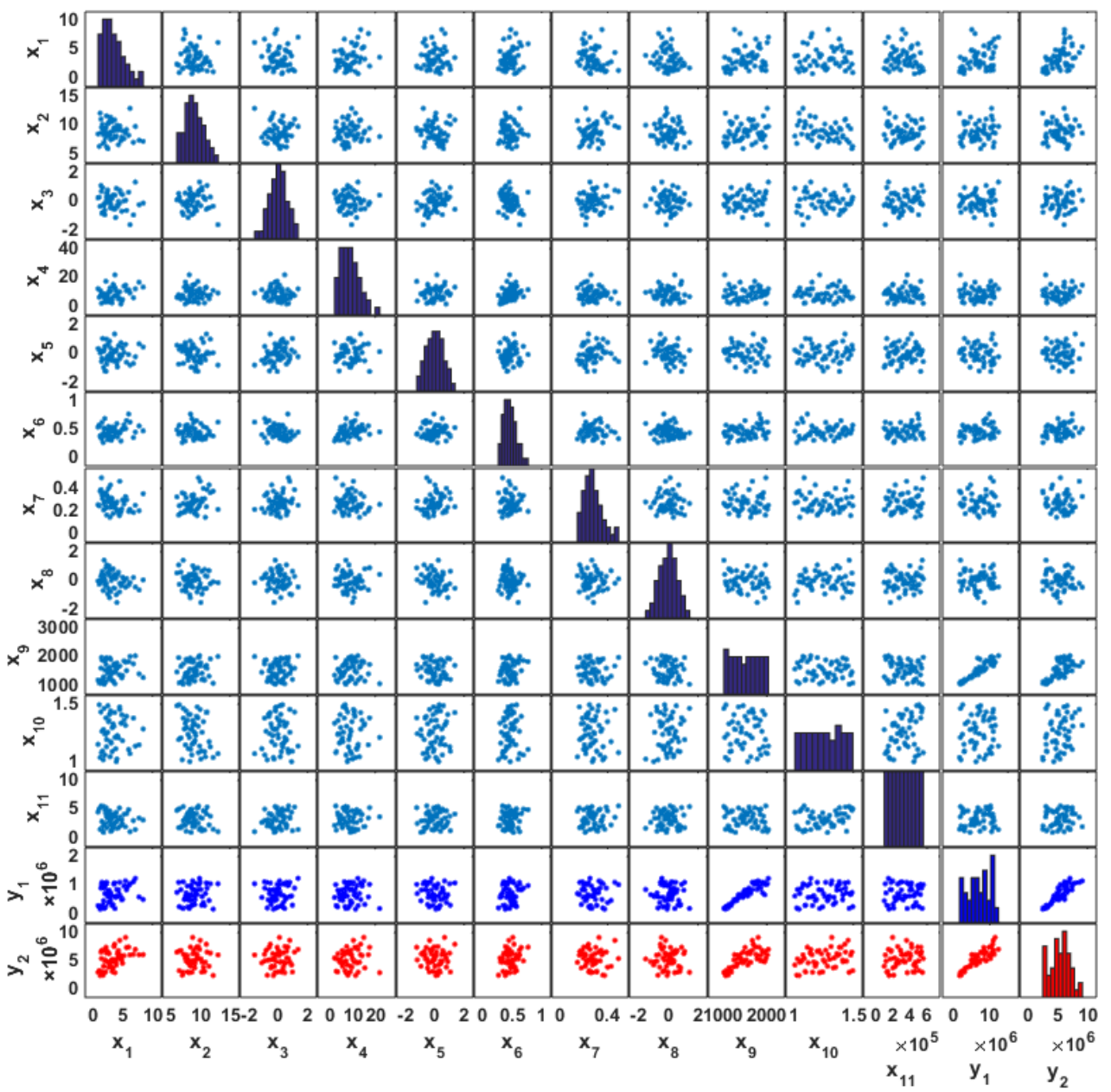

(b)

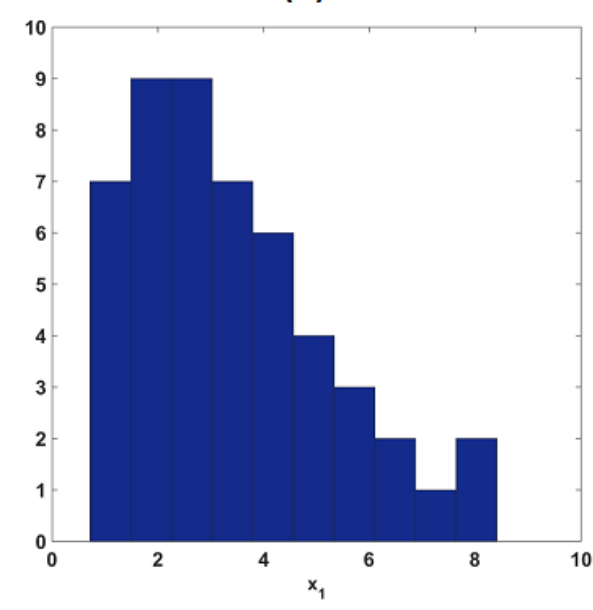

(c)

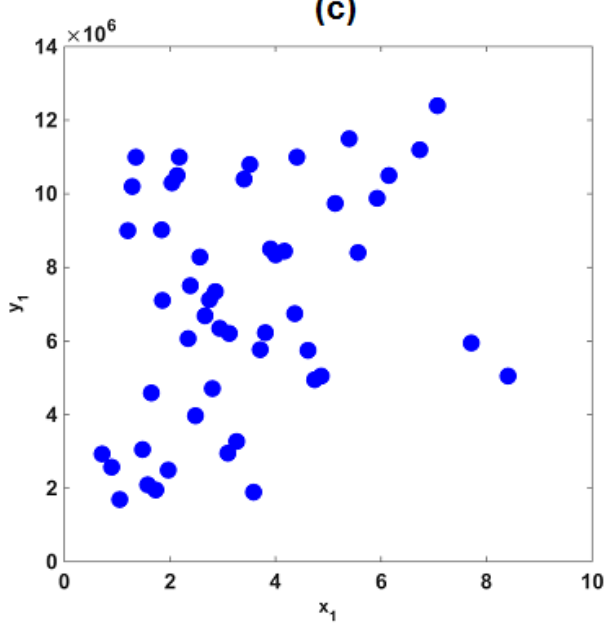

Fig 5. Summary of 50 scenarios: (a) scatter plots of input parameters and effective tension loads, (b) histogram of input parameter $x_{1}$, and (c) scatter plot of input parameter $x_{1}$ versus load $y_{1}$. 


\subsection{Application of metamodel-based method}

In applying the metamodel-based approach, we use the data from the dynamic analysis-based method. The effect plots in Fig. 6 show the importance of the input parameters. Graphs are constructed for each input variable by sorting each vector of values in ascending order and then dividing them into three groups. Hence, the plots show the mean value for each group and the mean response. For example, we can see that parameter $x_{9}$ against response $y_{1}$ covers a wider range of response values than the other parameters, and therefore $x_{9}$ is the most important parameter for $y_{1}$.

It can also be seen from Fig. 6 that parameters $x_{3}, x_{5}$, and $x_{8}$, which describe the direction of the environmental forces, are the least important. We thus exclude them from the rest of the analysis.
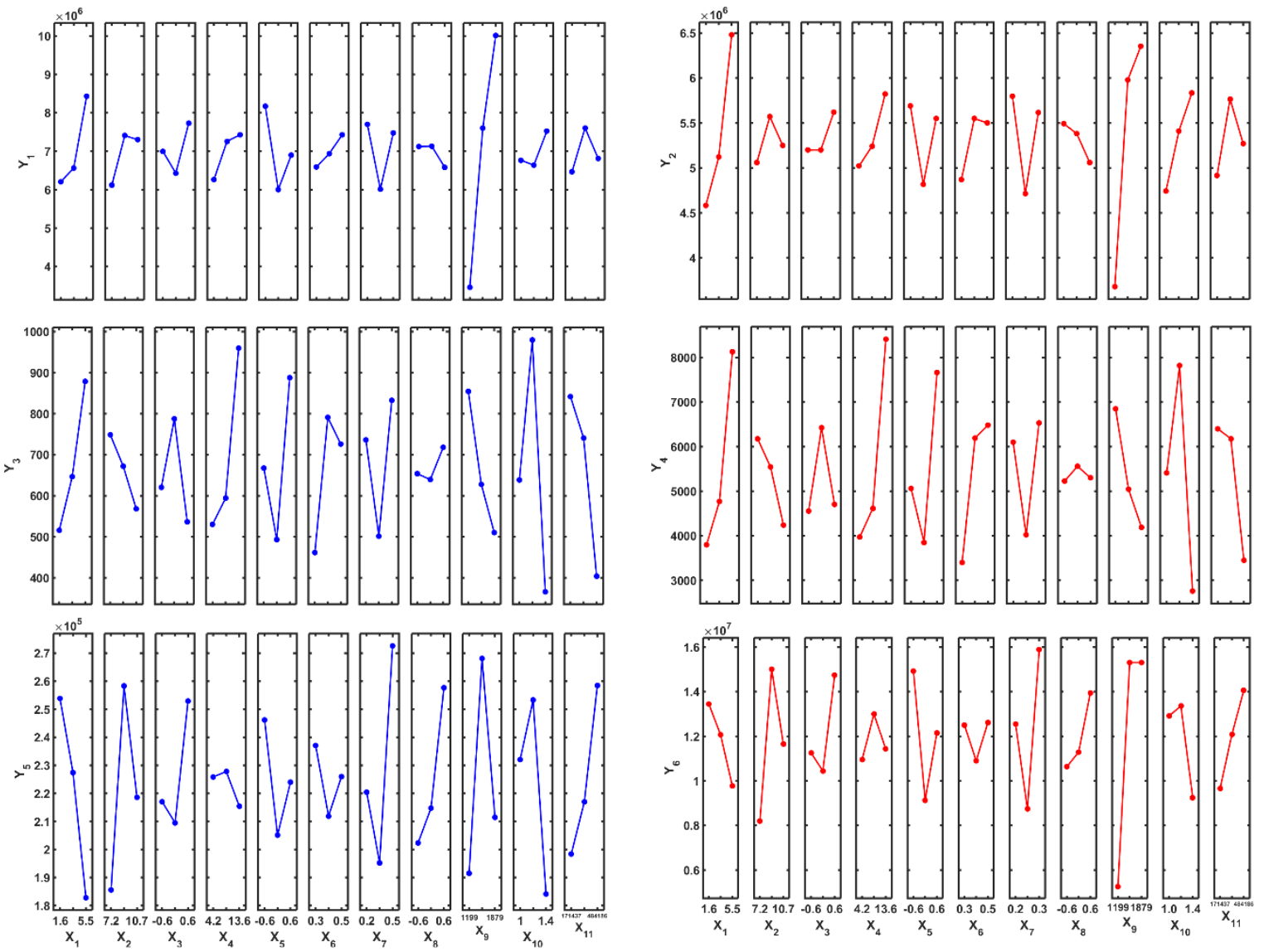

Fig 6. Main effect plots for responses at the top riser joint (blue) and bottom riser joint (red). 
Then we compute a Kriging metamodel for each load as a function of eight input parameters. It can be seen from Fig. 7 that the predicted loads exhibit a nonlinear response. Here, the metamodels are named $g_{1}, \ldots, g_{6}$, with sub-indexes matching those of the represented loads. The cross-validation in Fig. 8 confirms that the computed metamodels are able to reproduce the loads at the known points, and we therefore expect them to also perform well at interpolating the unknown points. The probabilistic distribution of the loads can subsequently be easily obtained via MCS.

(a) top riser joint effective tension

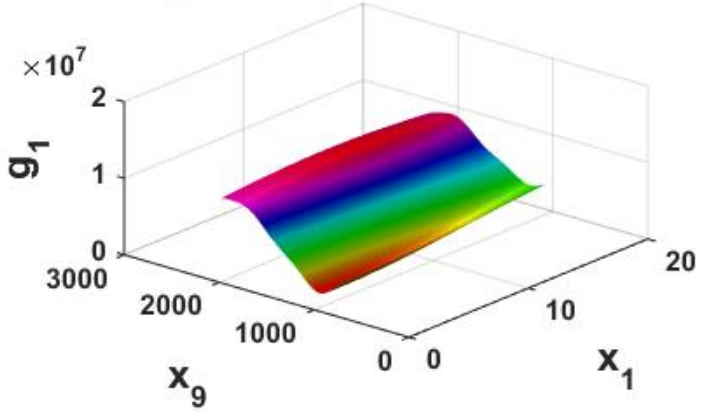

(c) top riser joint bending moment

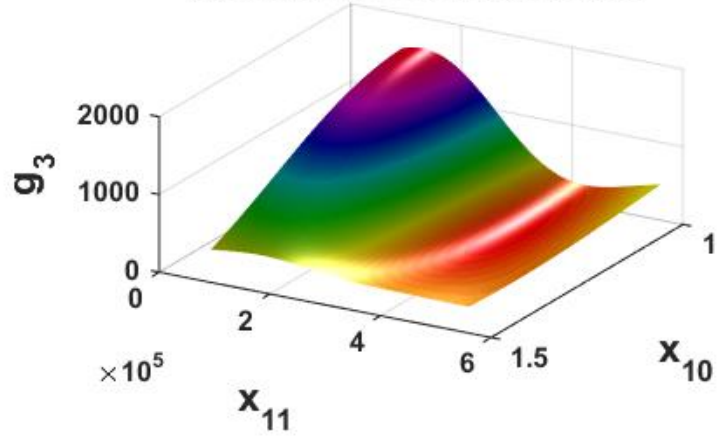

(e) top riser joint internal overpressure

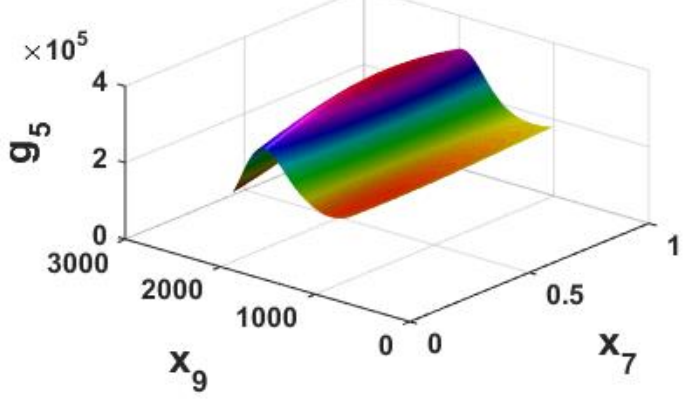

(b) bottom riser joint effective tension

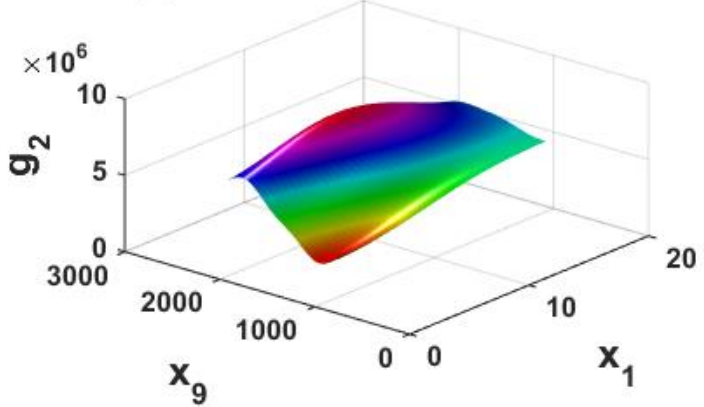

(d) bottom riser joint bending moment

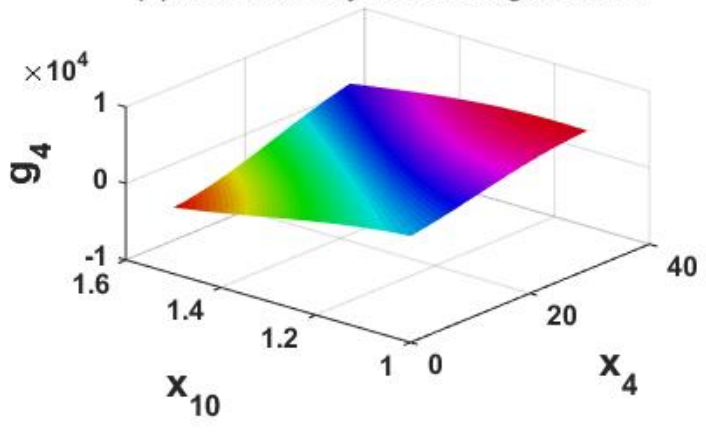

(f) bottom riser joint internal overpressure

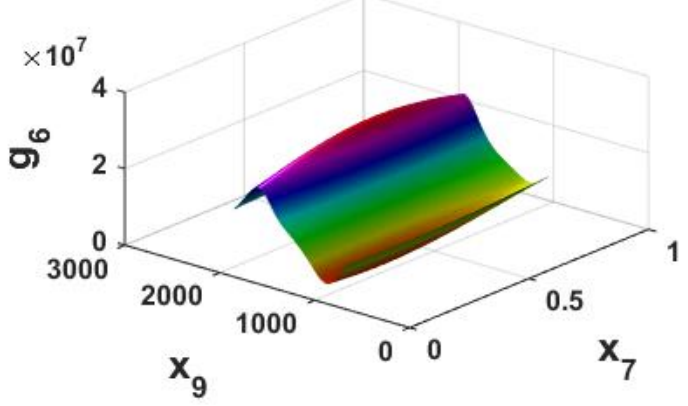

Fig. 7 Load metamodels as a function of the most relevant parameters (other parameters are fixed to their mean value). 

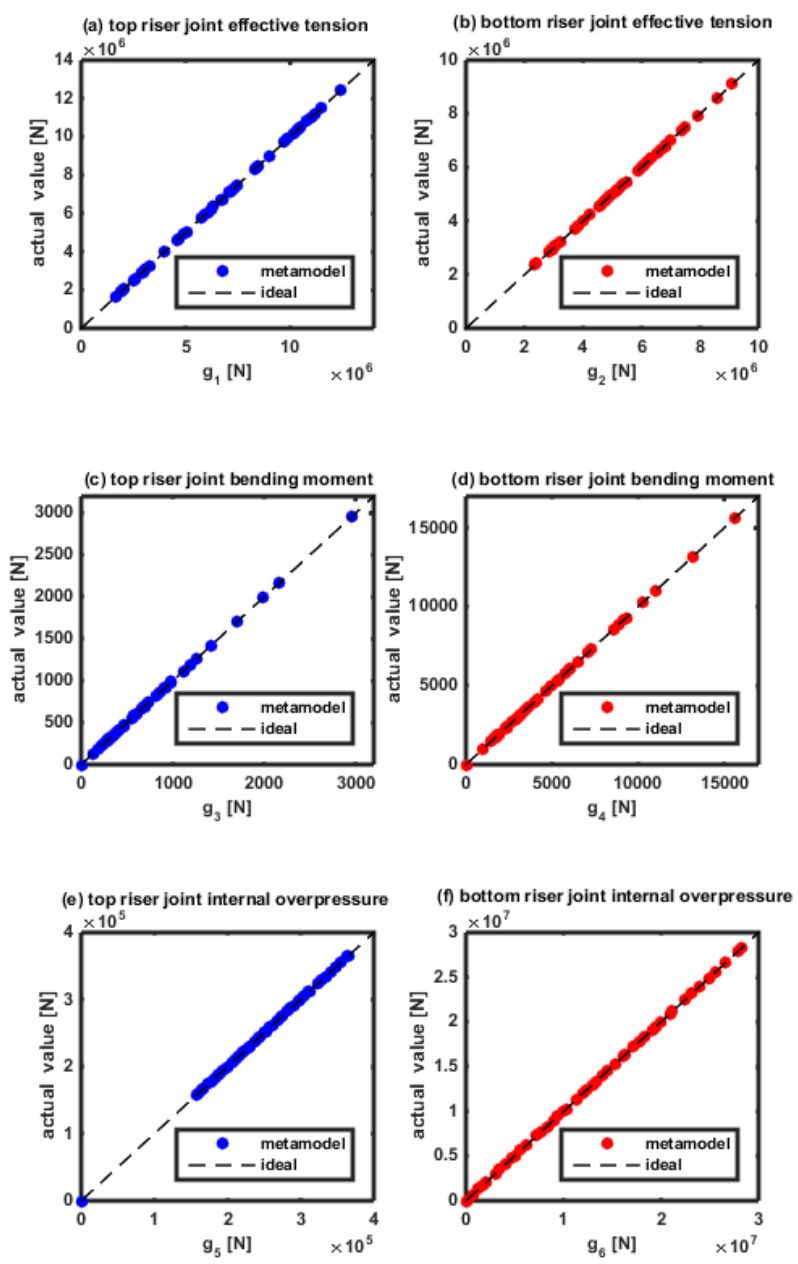

Fig. 8. Cross-validation of load metamodels.

\section{Results and discussion}

In this section, we discuss the derived probabilistic distribution of the riser loads. The influence of the PDF of internal fluid density is also addressed.

4.1 Quantified probabilistic distribution of riser loads 
For the dynamic analysis based method, Fig. 9 presents the data and probabilistic distributions that fulfill the best-fit functions. It can be observed that although the chosen distributions perform well for most of the sample points, they tend to overestimate the loads at a low exceedance probability. The bending moment at the bottom riser joint in Fig. 9(d) seems to be the exception.

(a) top riser joint effective tension

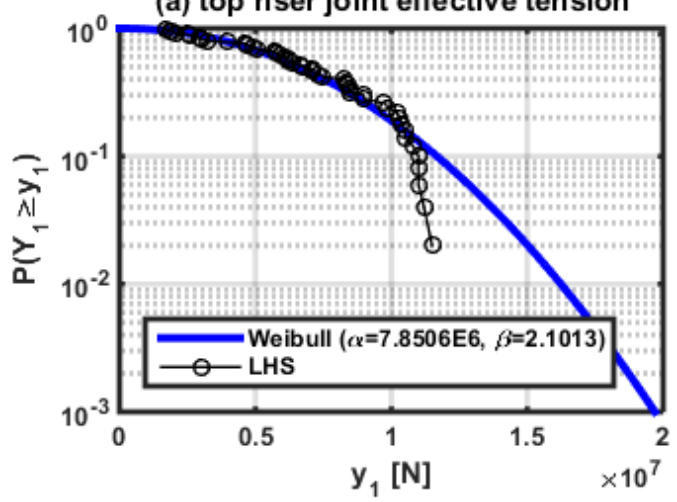

(c) top riser joint bending moment

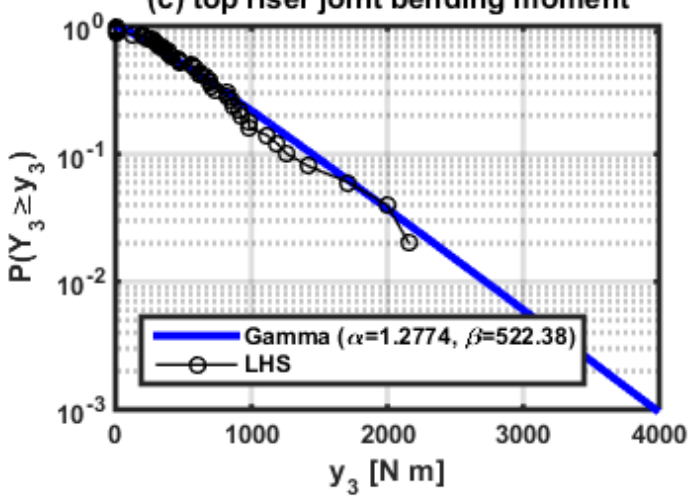

(e) top riser joint internal overpressure

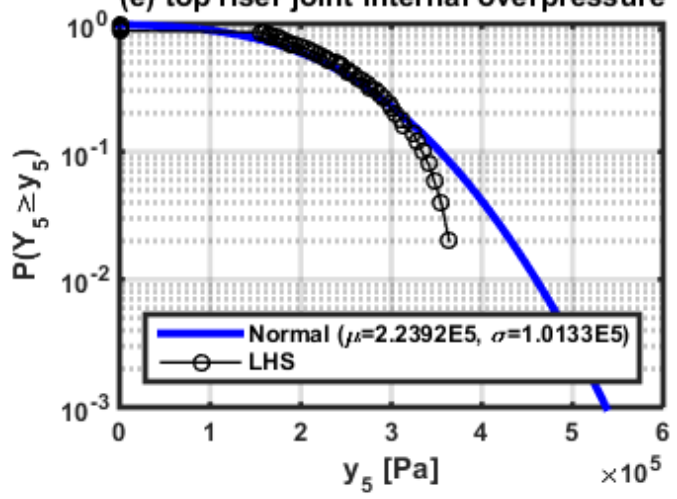

(b) bottom riser joint effective tension

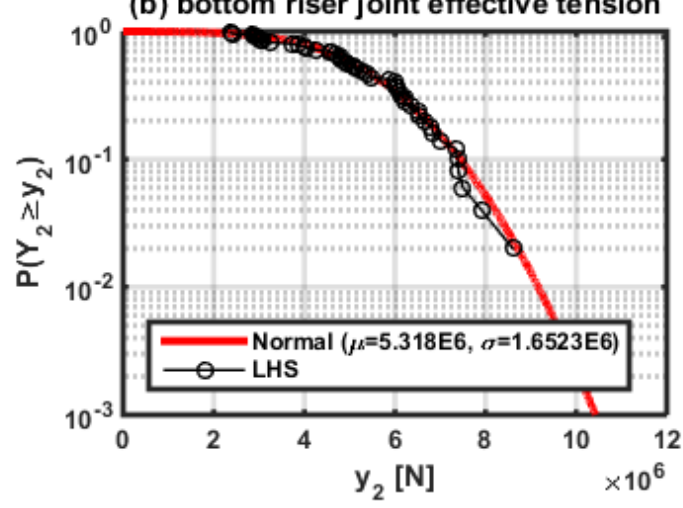

(d) bottom riser joint bending moment

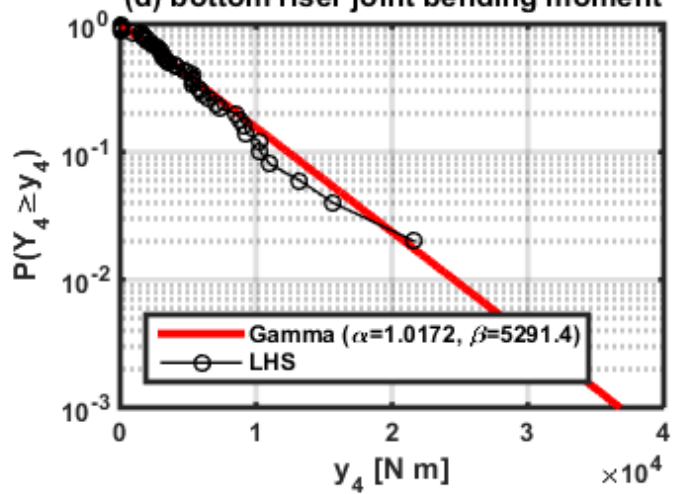

(f) bottom riser joint internal overpressure

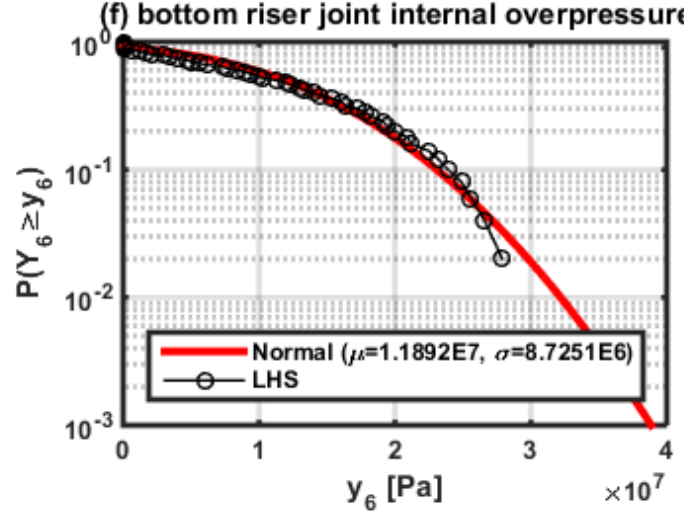

Fig. 9. Load probability of exceedance obtained from the dynamic analysis-based method. 
For the metamodel-based method, we run MCS to sample the input variables, which in turn feed metamodels $g_{1}, \ldots, g_{6}$. The results of 100,000 simulations and their comparison with the sampled data from the dynamic analysis-based method are plotted in Fig. 10. The approximate PDFs in the ordinate axis of the subfigures show that the metamodel-based method provides a more refined description of the probabilistic distribution of a load. For instance, the load PDFs in the metamodel approach are bimodal in Figs. 10(c), (d), (k), and (I), and trimodal in (a) and (b). These PDFs cannot be predicted by the best-fit distributions in the dynamic analysis-based method. In general, the PDF of a load in the metamodel approach exhibits high density at the middle of the distribution, which consequently reduces the density at its upper tail. 

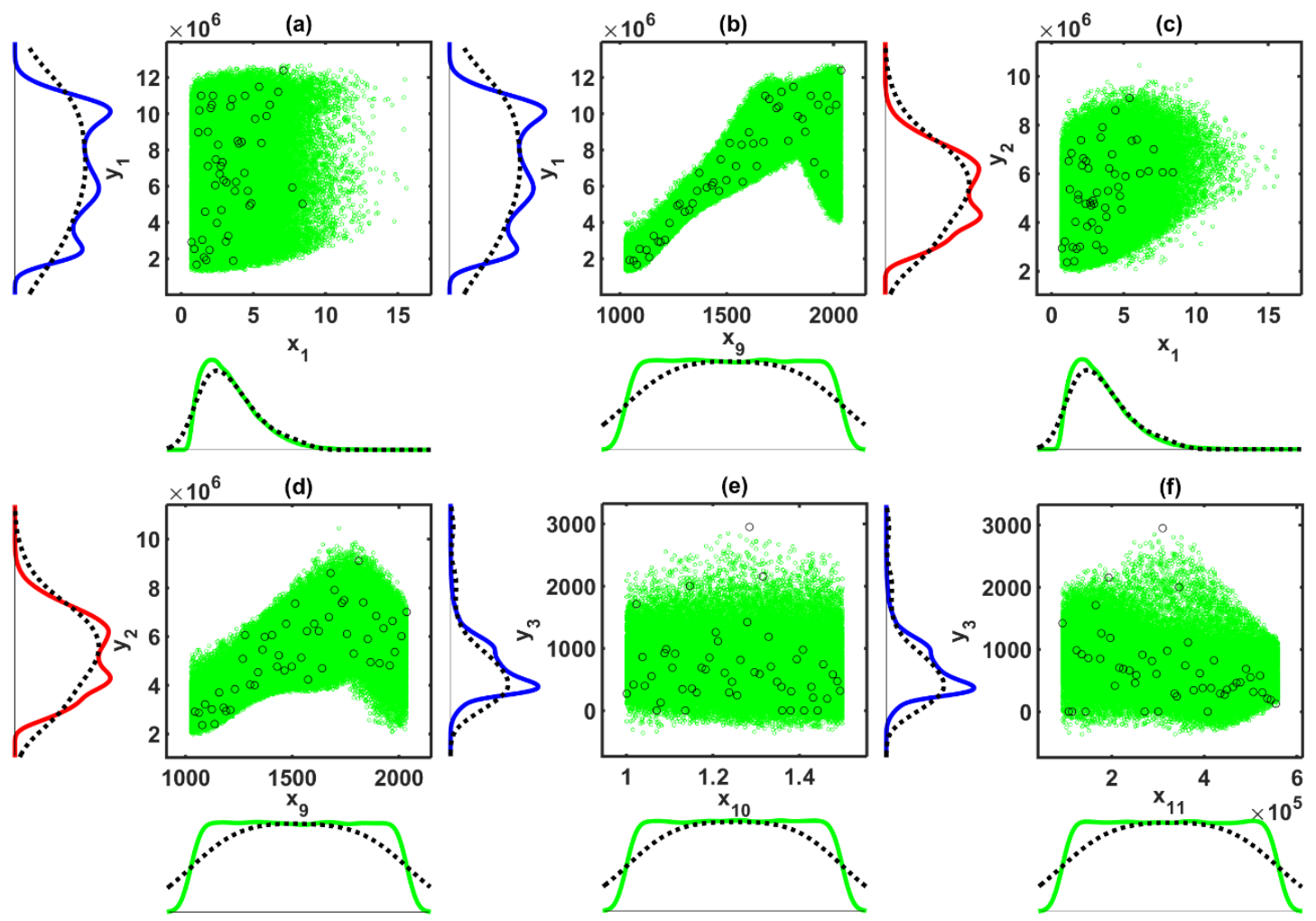

(e)
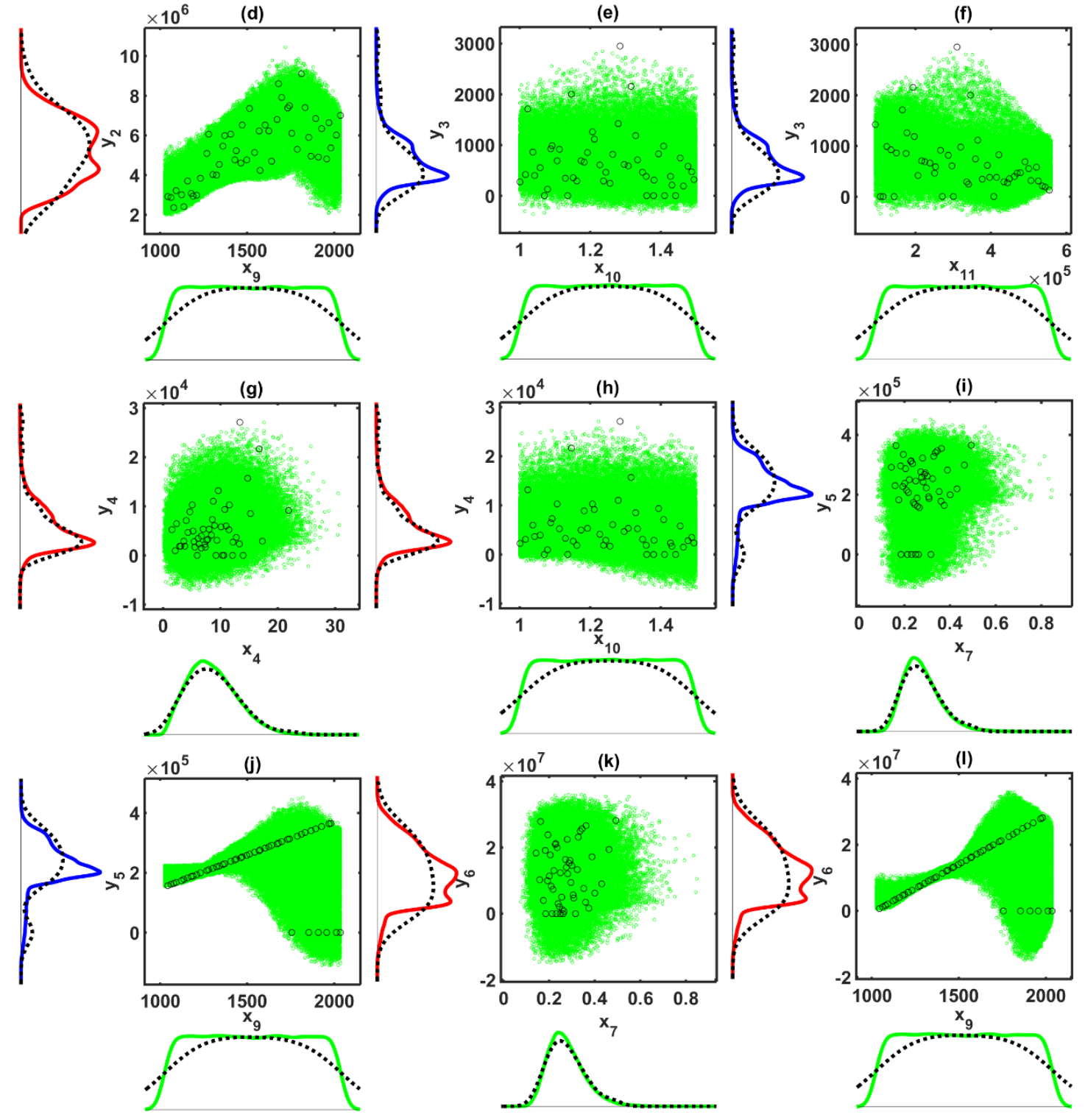

Fig. 10. Scatter plots of dynamic analysis-based method (black) and metamodel based-method results after MCS (green). 
The exceedance curve probabilities obtained from the two approaches are compared in Fig. 11, which shows a reasonable degree of agreement between them for probabilities of exceedance higher than 0.8 , but marked deviation for lower exceedance probabilities. Again, it is quite evident that the dynamic analysis-based method overrates extreme loads.

(a) top riser joint effective tension

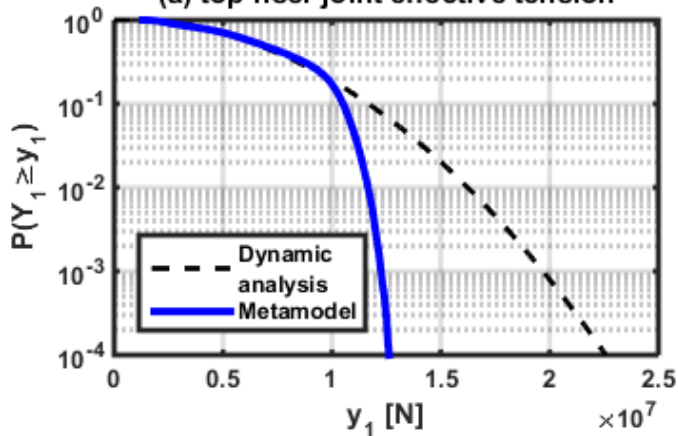

(c) top riser joint bending moment

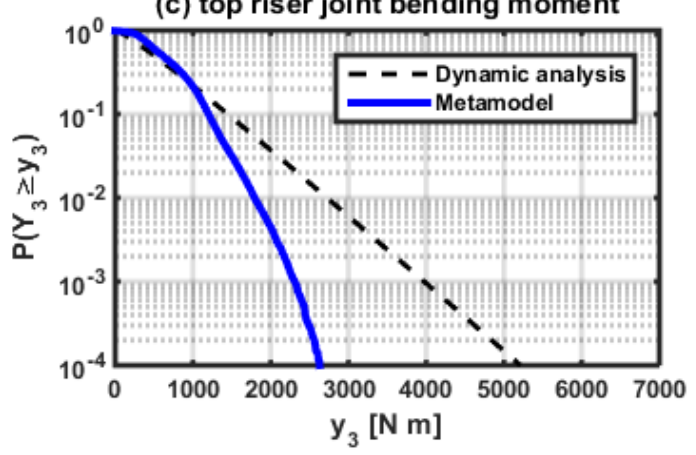

(e) top riser joint internal overpressure

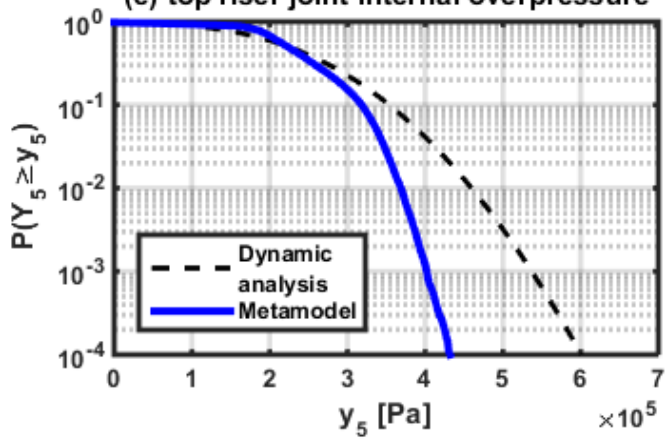

(b) bottom riser joint effective tension

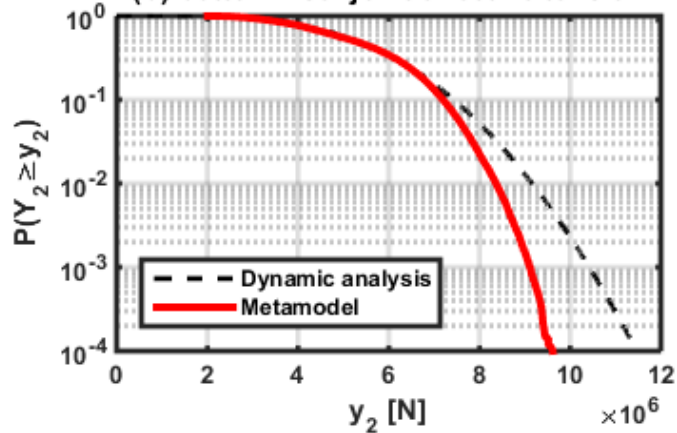

(d) bottom riser joint bending moment

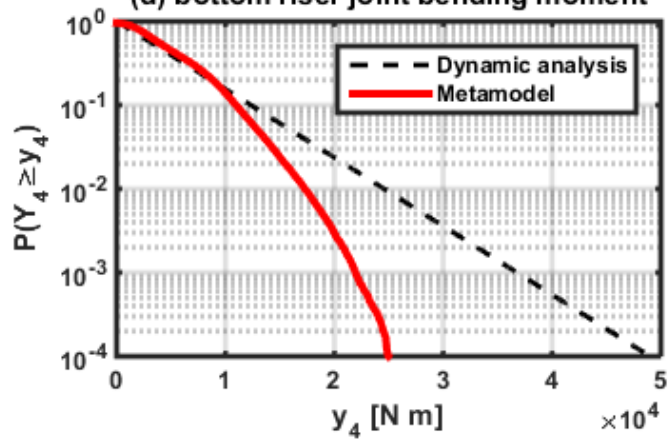

(f) bottom riser joint internal overpressure

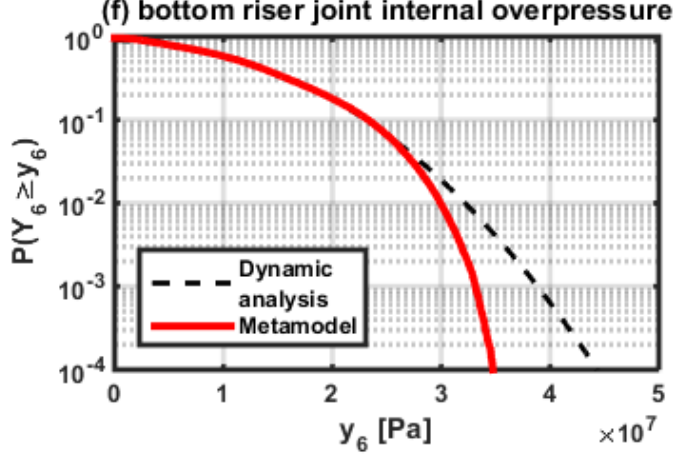

Fig. 11. Comparison of load probabilities of exceedance for dynamic analysis-based method versus metamodel-based method. 
We believe that a possible source of discrepancy between the two methods is the operational limits of the marine drilling riser. Remember that the riser is disconnected when operating guidelines are not fulfilled, and the probabilistic distribution consists of two overlapping processes: riser loading in the connected mode and loading in the disconnected mode. Moreover, this condition implies that the load cannot grow monotonically as a function of increasing the input parameters (see Fig. 7). Similar findings can be found in the literature; for example, Farnes and Moan (1993) observed that the Weibull distribution produces an over-conservative prediction of the loads on a permanent flexible riser system because of increased drag damping.

\subsection{Influence of internal fluid density}

It is well known that internal fluid density exerts a key influence on the responses of top-tensioned risers and compliant risers, which is confirmed in Fig. 6. We also investigate other distributions of $X_{9}$, as illustrated in Fig. 12. Care is exercised in using distributions that do not fall far from the known values to ensure the validity of the computed metamodels.

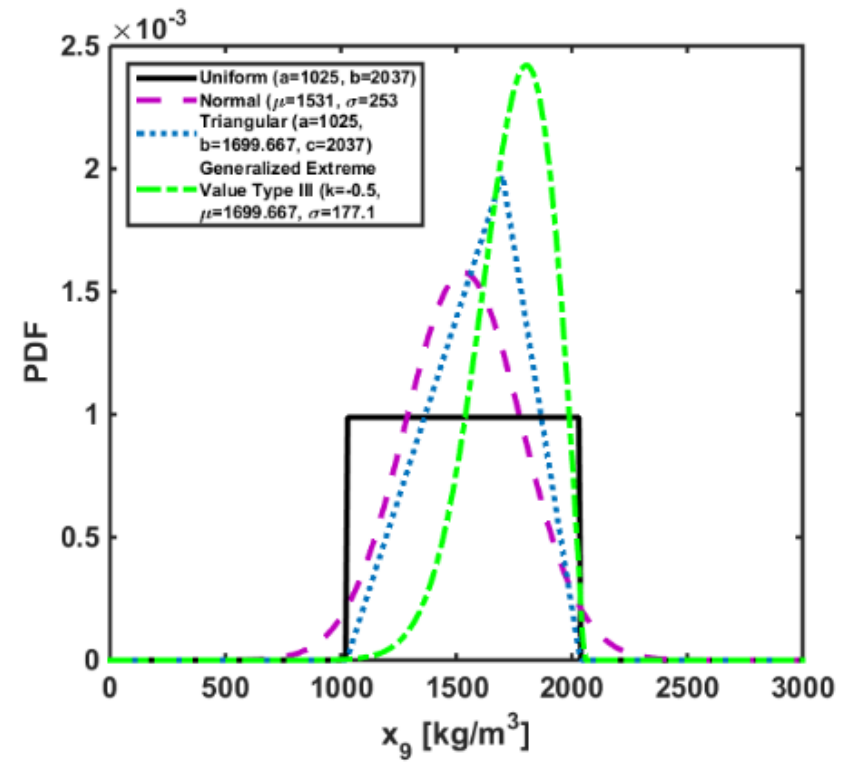

Fig 12. Distributions used to investigate the influence of internal fluid density. 
The resulting exceedance curves from MCS with 100,000 observations for each distribution are graphed in Fig. 13. It can be seen that there is little difference between the results for the uniform and normal distributions. However, the triangular and generalized extreme value type III distributions result in higher loads of the same probability of exceedance for effective tension and internal overpressure, whereas opposite results apply to the bending moment.

(a) top riser joint effective tension

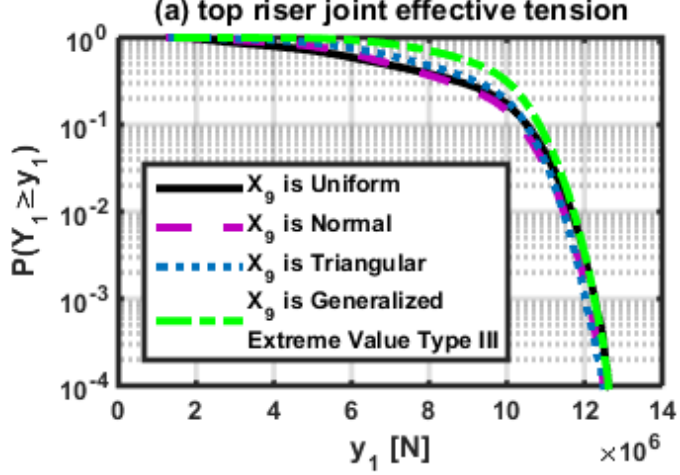

(c) top riser joint bending moment

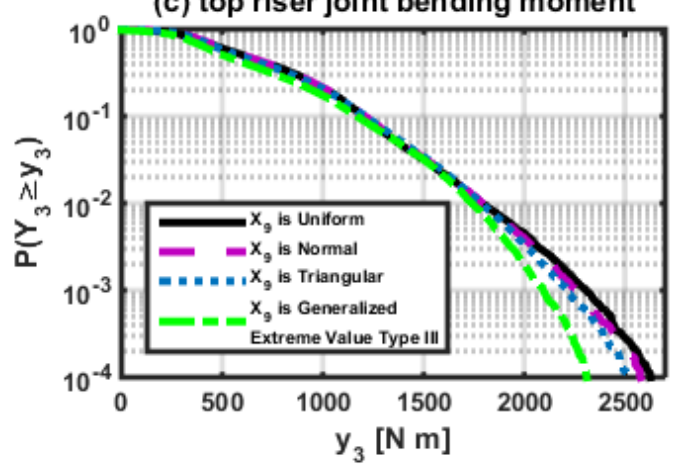

(e) top riser joint internal overpressure

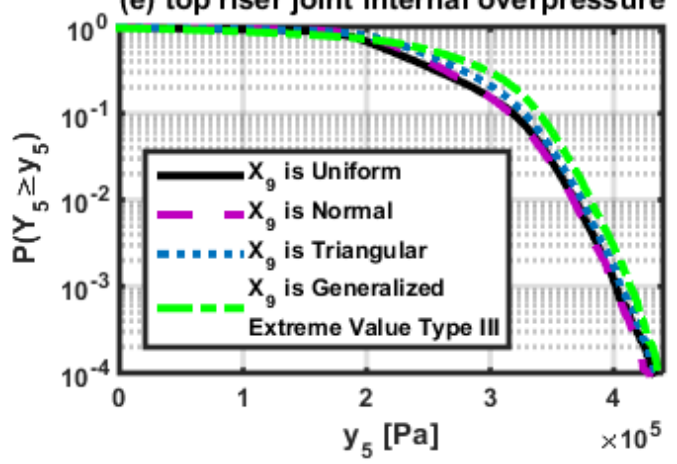

(b) bottom riser joint effective tension

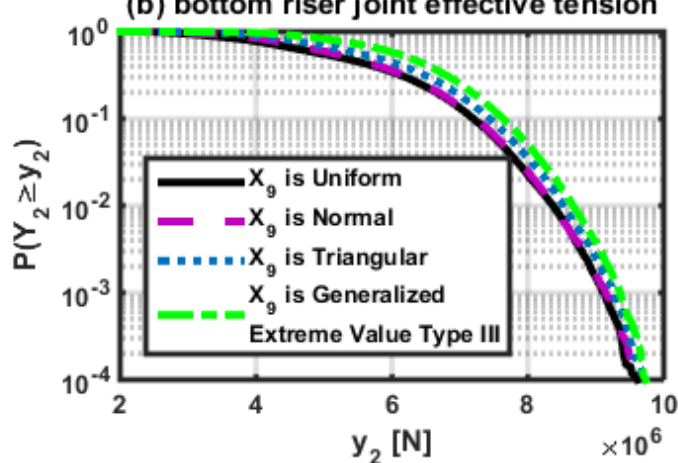

(d) bottom riser joint bending moment

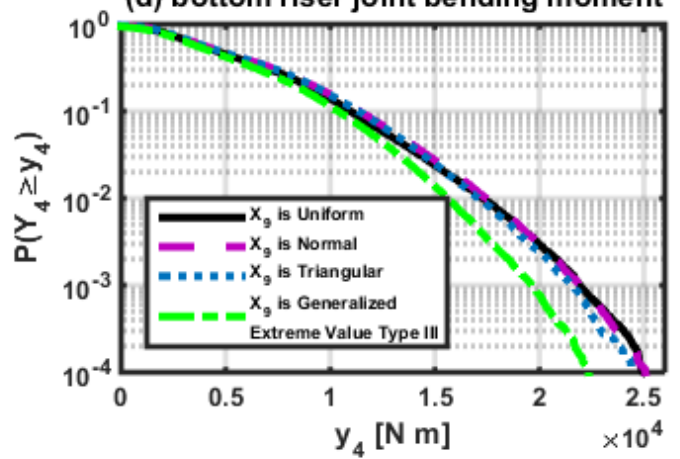

(f) bottom riser joint internal overpressure

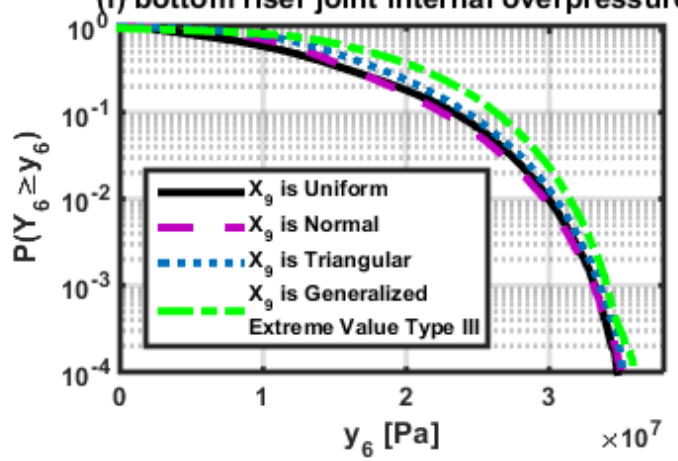

Fig 13. Influence of the probabilistic distribution of internal fluid density calculated using the metamodelbased method. 


\section{Conclusions}

The aim of the present study has been to identify the probabilistic characteristics of loads on a marine riser. Two methods of quantifying the probabilistic distribution of loads on marine risers are proposed herein. The first uses an efficient sampling technique to obtain scenarios, and then performs time-domain dynamic analysis and statistical analysis to fit a probabilistic distribution to the loads. The second requires the accomplishment of the first, then constructs a metamodel and applies MCS to derive the probabilistic distribution of the loads. A numerical example is presented to illustrate the application of both methods.

We find that the dynamic analysis based method gives over-conservative probabilistic load distribution, with an upper tail that extends to higher design values than the loads predicted by the metamodel-based method. Therefore, we are skeptical about using the dynamic analysis-based approach in reliability analysis. However, as this method is simpler than the second one, it may be possible to apply it in the early design stages, and then later update the calculations using the metamodel-based method.

Examination of the input random variables shows the internal fluid density exerts a major influence on the loads of a marine riser; nevertheless, its distribution seems to have little effect on the probabilistic distribution of the loads. For instance, a wider discrepancy in the load distributions is obtained by using one or the other method than by changing the probabilistic distribution of the internal fluid density.

The numerical example demonstrates the effectiveness of riser disconnection measures in reducing design loads, particularly when using the metamodel-based method.

\section{Acknowledgements}

This study was undertaken at the Lloyd's Register Foundation Research Centre of Excellence at Pusan National University, Busan, Korea. 


\section{References}

American Petroleum Institute, 1993. API RP16Q Recommended practice for design, selection, operation and maintenance of marine drilling riser systems.

Bai, Y., Chen, W., Xiong, H., Qiao, H., Yan, H., 2015. Analysis of steel strip reinforced thermoplastic pipe under internal pressure. Ships Offshore Struct. 5302, 1-8. doi:10.1080/17445302.2015.1063470

Bai, Y., Ruan, W., Yuan, S., He, X., Fu, J., 2014. 3D mechanical analysis of subsea manifold installation by drill pipe in deep water. Ships Offshore Struct. 9, 333-343. doi:10.1080/17445302.2013.783538

Baker, J.H.A., Liddle, D., 2015. The validation of flexible pipes and risers. Underw. Technol. 33, 59-64. doi:10.3723/ut.33.059

Chen, W., Li, M., Guo, S., Gan, K., 2014. Dynamic analysis of coupling between floating top-end heave and riser's vortex-induced vibration by using finite element simulations. Appl. Ocean Res. 48, 1-9. doi:10.1016/j.apor.2014.07.005

Chen, W., Li, M., Zheng, Z., Guo, S., Gan, K., 2015. Impacts of top-end vessel sway on vortex-induced vibration of the submarine riser for a floating platform in deep water. Ocean Eng. 99, 1-8. doi:10.1016/j.oceaneng.2015.03.002

Chen, Y., Seemann, R., Krause, D., Tay, T.-E., Tan, V.B., 2015. Prototyping and testing of composite riser joints for deepwater application. J. Reinf. Plast. Compos. 35, 95-110. doi:10.1177/0731684415607392

Chen, Y., Zhang, S., Wang, W., Xiong, M., 2014. Experimental study on axial load transfer behavior of a coiled tubing stuck in a marine riser. Proc. Inst. Mech. Eng. Part M J. Eng. Marit. Environ. doi:10.1177/1475090214563858

Chen, Y., Zhang, S., Wang, W., Xiong, M., Zhang, H., 2016. Experimental study on axial load transfer behavior of a coiled tubing stuck in a steel catenary riser: At the stage of the coiled tubing un-helical buckled. Proc. Inst. Mech. Eng. Part M J. Eng. Marit. Environ. doi:10.1177/1475090216642462

Clarke, T., Jacques, R., Bisognin, A., Camerini, C., Damasceno, S., Strohaecker, T., 2011. Monitoring the 
structural integrity of a flexible riser during a full-scale fatigue test. Eng. Struct. 33, 1181-1186. doi:10.1016/j.engstruct.2010.12.039

Connaire, A., O'Brien, P., Harte, A., O'Connor, A., 2015. Advancements in subsea riser analysis using quasi-rotations and the Newton-Raphson method. Int. J. Non. Linear. Mech. 70, 47-62. doi:10.1016/j.ijnonlinmec.2014.10.021

Costache, A., Glejbøl, K., Sivebæk, I.M., Berggreen, C., 2016. Improved Friction Joint with Self-locking Grips. J. Offshore Mech. Arct. Eng. 138, 51401-1-51401-8. doi:10.1115/1.4033331

Dai, H.L., Abdelkefi, A., Wang, L., Liu, W.B., 2015. Time-delay feedback controller for amplitude reduction in vortex-induced vibrations. Nonlinear Dyn. 80, 59-70. doi:10.1007/s11071-014-1851-x

Det Norske Veritas, 2010. Recommended practice DNV-RP-C205 Environmental conditions and environmental loads, Dnv.

Dong, L., Huang, Y., Zhang, Q., Liu, G., 2013. Taper design and non-linear analysis of bend stiffeners at the riser-vessel interface. Ships Offshore Struct. 8, 189-199. doi:10.1080/17445302.2012.707378

Faltinsen, O.M., 1990. Sea loads on ships and offshore structures. Cambridge University Press, Cambridge.

Fang, K., Li, R.Z., Sudjianto, A., 2006. Design and modeling for computer experiments, Computer Science and Data Analysis Series. Chapman \& Hall/CRC, Boca Raton.

Farnes, K.-A., Moan, T., 1993. Extreme Response of a Flexible Riser System Using a Complete Nonlinear Long-Term Approach, in: Proceedings of the Third International Offshore and Polar Engineering Conference. Singapore, pp. 321-330.

Gao, Y., Fu, S., Ma, L., Chen, Y., 2016. Experimental investigation of the response performance of VIV on a flexible riser with helical strakes. Ships Offshore Struct. 11, 113-128.

doi:10.1080/17445302.2014.962788

Gao, Y., Low, Y.M., 2016. An efficient importance sampling method for long-term fatigue assessment of deepwater risers with time domain analysis. Probabilistic Eng. Mech. 45, 102-114. 
doi:10.1016/j.probengmech.2016.04.003

Gu, J., Pinto, W.T., Levi, C., Duan, M., 2013a. An experimental study of the spanwise correlation of vortex shedding in the towing tank. Ships Offshore Struct. 8, 517-523. doi:10.1080/17445302.2012.726706

Gu, J., Wang, Y., Zhang, Y., Duan, M., Levi, C., 2013b. Analytical solution of mean top tension of long flexible riser in modeling vortex-induced vibrations. Appl. Ocean Res. 41, 1-8. doi:10.1016/j.apor.2013.01.004

Guimarães Pestana, R., Edward Roveri, F., Franciss, R., Bruno Ellwanger, G., 2016. Marine riser emergency disconnection analysis using scalar elements for tensioner modelling. Appl. Ocean Res. 59, 83-92. doi:10.1016/j.apor.2016.05.004

Guo, L., Duan, M., Wang, Y., Yu, F., 2014. Experimental investigation on dynamic model testing of a deep-water Riser Support by truncated hybrid method. Ships Offshore Struct. 9, 344-353. doi:10.1080/17445302.2013.785772

Institut Français du Pétrole, 1999. Drilling data handbook, Seventh. ed. Éditions Technip, Paris.

Josefsson, P.M., Dalton, C., 2010. An Analytical/Computational Approach in Assessing Vortex-Induced Vibration of a Variable Tension Riser. J. Offshore Mech. Arct. Eng. 132, 31302. doi:10.1115/1.4000500

Katifeoglou, S.A., Chatjigeorgiou, I.K., 2015. Dynamics of shell-like tubular segments at the sagbend region of a steel catenary riser. Ships Offshore Struct. 5302, 1-14. doi:10.1080/17445302.2015.1074644

Katifeoglou, S.A., Chatjigeorgiou, I.K., 2012. Dynamic interaction of catenary risers with the seafloor. Appl. Ocean Res. 38, 1-15. doi:10.1016/j.apor.2012.06.001

Kuiper, G.L., Brugmans, J., Metrikine, A. V., 2008. Destabilization of deep-water risers by a heaving platform. J. Sound Vib. 310, 541-557. doi:10.1016/j.jsv.2007.05.020

Lee, H., Roh, M. II, Ham, S.H., Ha, S., 2015. Dynamic simulation of the wireline riser tensioner system for a mobile offshore drilling unit based on multibody system dynamics. Ocean Eng. 106, 485-495. 
doi:10.1016/j.oceaneng.2015.07.028

Li, F.Z., Low, Y.M., 2014. Influence of low-frequency vessel motions on the fatigue response of steel catenary risers at the touchdown point. Ships Offshore Struct. 9, 134-148.

doi:10.1080/17445302.2012.740874

Li, F.Z., Low, Y.M., 2012. Fatigue reliability analysis of a steel catenary riser at the touchdown point incorporating soil model uncertainties. Appl. Ocean Res. 38, 100-110. doi:10.1016/j.apor.2012.07.005

Liu, X., Chen, G., Chang, Y., Liu, K., Zhang, L., Xu, L., 2013. Analyses and countermeasures of deepwater drilling riser grounding accidents under typhoon conditions. Pet. Explor. Dev. 40, 791795. doi:10.1016/S1876-3804(13)60106-8

Low, Y.M., Srinil, N., 2016. VIV fatigue reliability analysis of marine risers with uncertainties in the wake oscillator model. Eng. Struct. 106, 96-108. doi:10.1016/j.engstruct.2015.10.004

Ma, P., Spencer, D., 2014. Numerical Vortex-Induced Vibration Prediction of Marine Risers in TimeDomain Based on a Forcing Algorithm 136, 1-9. doi:10.1115/1.4027385

Mao, L., Liu, Q., Zhou, S., Jiang, W., Liu, Z., Peng, T., 2015. Vortex-induced vibration mechanism of drilling riser under shear flow. Pet. Explor. Dev. 42, 112-118. doi:10.1016/S1876-3804(15)60013-1

Mao, L., Liu, Q., Zhou, S., Wang, G., Fu, Q., 2016. Deep water drilling riser mechanical behavior analysis considering actual riser string configuration. J. Nat. Gas Sci. Eng. 33, 240-254. doi:10.1016/j.jngse.2016.05.031

Mousavi, M.E., Reza, Z., Vijayaraghavan, V., Haverty, K., Upadhye, S., 2016. A Simplified Method for Quantitative Reliability Analysis of SCRs. J. Offshore Mech. Arct. Eng. 138, 11601-1-11601-8. doi:10.1115/1.4031822

Nazir, M., Khan, F., Amyotte, P., 2008. Fatigue reliability analysis of deep water rigid marine risers associated with Morison-type wave loading. Stoch. Environ. Res. Risk Assess. 22, 379-390. doi:10.1007/s00477-007-0125-2 
Paik, J.K., Czujko, J., Kim, B.J., Seo, J.K., Ryu, H.S., Ha, Y.C., Janiszewski, P., Musial, B., 2011. Quantitative assessment of hydrocarbon explosion and fire risks in offshore installations. Mar. Struct. 24, 73-96. doi:10.1016/j.marstruc.2011.02.002

Paik, J.K., Lee, S.E., Kim, B.J., Seo, J.K., Ha, Y.C., Matsumoto, T., Byeon, S.H., 2015. Toward a Probabilistic Approach to Determine Nominal Values of Tank Slosing Loads in Structural Design of Liquefied Natural Gas FPSOs. J. Offshore Mech. Arct. Eng. 137, 21801. doi:10.1115/1.4029666

Paik, J.K., Thayamballi, A.K., Park, Y. II, Hwang, J.S., 2004. A time-dependent corrosion wastage model for seawater ballast tank structures of ships. Corros. Sci. 46, 471-486. doi:10.1016/S0010$938 \times(03) 00145-8$

Park, K.S., Kim, Y.T., Kim, D.K., Yu, S.Y., Choi, H.S., 2015. A new method for strake configuration design of Steel Catenary Risers. Ships Offshore Struct. 5302, 1-20. doi:10.1080/17445302.2014.999479

Permana, W.E., 2012. A Comparative Analysis of 21 inch and 16 inch Drilling Riser for Deepwater Application. University of Stavanger. doi:10.1007/BF03192151

Pham, D.-C., Sridhar, N., Qian, X., Sobey, A.J., Achintha, M., Shenoi, A., 2016. A review on design, manufacture and mechanics of composite risers. Ocean Eng. 112, 82-96. doi:10.1016/j.oceaneng.2015.12.004

Seo, J.K., Kim, D.C., Ha, Y.C., Kim, B.J., Paik, J.K., 2013. A methodology for determining efficient gas detector locations on offshore installations. Ships Offshore Struct. 8, 524-535. doi:10.1080/17445302.2012.713219

Shi, C., Manuel, L., Tognarelli, M.A., 2014. Empirical Procedures for Long-Term Prediction of Fatigue Damage for an Instrumented Marine Riser. J. Offshore Mech. Arct. Eng. 136, 31402-1-31402-10. doi:10.1115/1.4027654

Shields, M.D., Zhang, J., 2016. The generalization of Latin hypercube sampling. Reliab. Eng. Syst. Saf. 148, 96-108. doi:10.1016/j.ress.2015.12.002

Sun, X.S., Chen, Y., Tan, V.B.C., Jaiman, R.K., Tay, T.E., 2014. Homogenization and Stress Analysis of 
Multilayered Composite Offshore Production Risers. J. Appl. Mech. 81, 31003-1-31003-12. doi:10.1115/1.4024695

Ulaganathan, S., Couckuyt, I., Deschrijver, D., Laermans, E., Dhaene, T., 2015. A Matlab toolbox for Kriging metamodelling. Procedia Comput. Sci. 51, 2708-2713. doi:10.1016/j.procs.2015.05.395

Wang, E., Xiao, Q., 2016. Numerical simulation of vortex-induced vibration of a vertical riser in uniform and linearly sheared currents. Ocean Eng. 121, 492-515. doi:10.1016/j.oceaneng.2016.06.002

Wang, J., Duan, M., He, T., Jing, C., 2014. Numerical solutions for nonlinear large deformation behaviour of deepwater steel lazy-wave riser. Ships Offshore Struct. 9, 655-668. doi:10.1080/17445302.2013.868622

Wang, J., Duan, M., Luo, J., 2015a. Mathematical model of steel lazy-wave riser abandonment and recovery in deepwater. Mar. Struct. 41, 127-153. doi:10.1016/j.marstruc.2015.02.002

Wang, J., Duan, M., Wang, Y., Li, X., Luo, J., 2015b. A nonlinear mechanical model for deepwater steel lazy-wave riser transfer process during installation. Appl. Ocean Res. 50, 217-226. doi:10.1016/j.apor.2015.02.004

Wang, Y., Gao, D., Fang, J., 2015a. Study on lateral vibration analysis of marine riser in installation-via variational approach. J. Nat. Gas Sci. Eng. 22, 523-529. doi:10.1016/j.jngse.2014.12.012

Wang, Y., Gao, D., Fang, J., 2015b. Coupled dynamic analysis of deepwater drilling riser under combined forcing and parametric excitation. J. Nat. Gas Sci. Eng. 27, 1739-1747. doi:10.1016/j.jngse.2015.10.038

Wang, Y., Gao, D., Fang, J., 2014a. Static analysis of deep-water marine riser subjected to both axial and lateral forces in its installation. J. Nat. Gas Sci. Eng. 19, 84-90. doi:10.1016/j.jngse.2014.04.019

Wang, Y., Gao, D., Fang, J., 2014b. Axial dynamic analysis of marine riser in installation. J. Nat. Gas Sci. Eng. 21, 112-117. doi:10.1016/j.jngse.2014.07.031

Wei, Y., Yang, J., Chen, G., Hu, Z., 2012. Experimental study on the hydrodynamic performance of FDPSO and SRV. Ships Offshore Struct. 7, 357-369. doi:10.1080/17445302.2011.624389 
Xiao, F., Yang, H.Z., 2014. Probabilistic assessment of parametric instability of a top tensioned riser in irregular waves. J. Mar. Sci. Technol. 19, 245-256. doi:10.1007/s00773-013-0243-0

Xu, T., Cater, J.E., 2016. Numerical simulation of flow past a curved cylinder in uniform and logarithmic flow. Ships Offshore Struct. 5302, 1-7. doi:10.1080/17445302.2016.1139259

Yang, H., Wang, Z., Xiao, F., 2016. Parametric resonance of submerged floating pipelines with bifrequency parametric and vortex-induced oscillations excitations. Ships Offshore Struct. 5302, 1-9. doi:10.1080/17445302.2016.1171590

Yang, H., Xiao, F., 2014. Instability analyses of a top-tensioned riser under combined vortex and multifrequency parametric excitations. Ocean Eng. 81, 12-28. doi:10.1016/j.oceaneng.2014.02.006

Yang, H., Xiao, F., Xu, P., 2013. Parametric instability prediction in a top-tensioned riser in irregular waves. Ocean Eng. 70, 39-50. doi:10.1016/j.oceaneng.2013.05.002

Yang, H.Z., Zheng, W., 2011. Metamodel approach for reliability-based design optimization of a steel catenary riser. J. Mar. Sci. Technol. 16, 202-213. doi:10.1007/s00773-011-0121-6

Ye, M., Duan, M., Li, M., Chen, J., Tian, K., Han, F., Hu, Z., 2014. An active truncation method for simulating deep-water riser installation. Ships Offshore Struct. 9, 619-632. doi:10.1080/17445302.2013.879507

Ye, M., Duan, M., Li, Z., Chen, R., Wang, Y., Li, M., 2013. Novel installation methods and devices of steel catenary risers (SCR) in the South China Sea. Underw. Technol. 31, 93-104. doi:10.3723/ut.31.093

Zhang, Y., Duan, M., Wang, Y., Chu, G., 2015. Analytical study of the strength of adhesive joints of riser pipes. Ships Offshore Struct. 5302, 1-9. doi:10.1080/17445302.2015.1014254 